\title{
Post- operative Radiotherapy of Conjunctival Malignancies: A Series of 24 Cases
}

\author{
Asma Belaïd ${ }^{1,2}$, Chiraz Nasr ${ }^{1,2}$, Omar Jmour ${ }^{1,2}$, Aziz Cherif ${ }^{1,2}$, Hajer Kamoun', \\ Khalil Mahjoubi ${ }^{1,2}$, Rim Abidi ${ }^{1,2}$, Safia Yahiaoui ${ }^{1,2}$, Semia Zarraa ${ }^{1,2}$, Amani \\ Yousfi $^{1,2}$, Walid Gargouri ${ }^{1}$, Hedi Bouguila ${ }^{2,3}$, Mounir Besbes ${ }^{1}$, Farouk Benna ${ }^{1,2}$
}

${ }^{1}$ Radiation Oncology Department, Salah Azaïz Institute, Tunis, Tunisia. ${ }^{2}$ Faculty of Medicine of Tunis, Tunis-el Manar University, Tunis, Tunisia. ${ }^{3}$ Ophthalmology Department, Hedi Raïs Institute, Tunis, Tunisia.

\begin{abstract}
Objective: To assess the results of post-operative radiation therapy in the management of incompletely resected conjunctival malignancies. Methods: In this retrospective case series, we reviewed the clinical records of all cases of conjunctival tumors treated with post-operative radiotherapy in the radiation oncology department of Salah Azaïz Institute of Tunis, from January 1990 to December 2015. We focused on clinico-pathological characteristics, treatment modalities and patients' outcome. Results: Twenty four patients were enrolled in our study: 19 men and 5 women. The mean age of our patients was 54 years (range: 20 to 84). The mean basal diameter of the tumor was $11 \mathrm{~mm}$ (range 6 to $20 \mathrm{~mm}$ ). The mean tumor thickness was $4 \mathrm{~mm}$ (range 1 to 15 $\mathrm{mm}$ ). The most frequent histological type was squamous cell carcinoma in 23 cases. One patient had a malignant conjunctival fibrohistiocytoma. Radiation therapy was post-operative for positive or narrow surgical margins in all cases. Eighteen patients were treated with kilovoltage radiation therapy (KVRT). The mean delivered dose to the tumor bed was $64 \mathrm{~Gy}$ (range: 60 to $70 \mathrm{~Gy}$ ). Four patients were treated with an association of KVRT and Strontium 90 plaque brachytherapy. Two patients were treated only with Strontium 90 plaque brachytherapy ( 2 fractions of $17 \mathrm{~Gy}$ ). After a median follow-up of 110 months, 19 patients were alive with no evidence of local recurrence in 17 patients. Two patients had a local recurrence and were referred to surgery. Two patients were lost to follow up. The 5-year relapse free survival rate was $90.9 \%$. Radiation-induced side effects were conjunctivitis, cataract, eye watering and glaucoma. Conclusion: Post-operative radiation therapy allows good local control with acceptable toxicities in conjunctival malignancies. Management of these tumors needs a broad collaboration between ophthalmologists and radiation oncologists, to allow a conservative treatment with the lowest rates of local recurrence.
\end{abstract}

Keywords: Radiotherapy- Conjunctival Malignancies- Malignant tumors

Asian Pac J Cancer Biol, 2 (1), 3-8

\section{Introduction}

Malignant tumors of the conjunctiva account for $30 \%$ of all conjunctival tumors in adults [1]. The type and frequency of conjunctival tumors differ with demographic features such as age and race, systemic immune status, and chronic exposures [2]. The most common conjunctival malignancy is ocular surface squamous neoplasia (OSSN) including conjunctival intraepithelial neoplasia (CIN) and squamous cell carcinoma (SCC). Predisposing conditions
Submission Date: 11/14/2016 Acceptance Date: 01/25/2017

Corresponding Author:

Dr. Farouk Benna

${ }^{1}$ Radiation Oncology Department, Salah Azaïz Institute, Tunis, Tunisia.

${ }^{2}$ Faculty of Medicine of Tunis, Tunis-el Manar University, Tunis, Tunisia.

Email: farouk.benna@yahoo.fr 
but adjuvant treatments are often needed to reduce local recurrences. Adjuvant treatments include cryotherapy, topical chemotherapy (mitomycin C, 5-fluorouracil), radiotherapy, immunotherapy, topical antiviral medication and/or photodynamic therapy.

The aim of this study was to assess the results of post-operative radiation therapy in the management of incompletely resected conjunctival malignancies.

\section{Materials and Methods}

\section{Study population}

In this retrospective case series, we included all patients with a pathologically confirmed conjunctival malignancy, treated in the radiation oncology department of Salah Azaïz Institute of Tunis, from January 1990 to December 2015.

The decision of radiation therapy was taken jointly by the ophthalmologist and the radiation oncologist and confirmed in the radiotherapy department medical weekly staff. Postoperative radiotherapy was indicated if pathological examination of the surgical specimen revealed findings indicative of a high risk of local recurrences, such as positive or close surgical margins (less than $3 \mathrm{~mm}$ tumor-free margins).

The ophthalmologist had to indicate the conjunctival tumor bed on a drawn pattern or directly on the patient the day of the radiotherapy planning. The clinical target volume (CTV) encompassed the tumor bed with a 5 $\mathrm{mm}$ margin. The planning target volume (PTV) was equal to the CTV. Patients were treated with external beam radiotherapy (EBRT) and/or ocular plaque brachytherapy. The general objective was to deliver a biologically effective total dose of 60-70 Gy to the PTV. EBRT used filtered kilovoltage radiotherapy (KVRT) beams and brachytherapy used high-dose-rate Strontium 90 ophthalmic applicators (Figure 1).

The choice of KVRT energy depended on the tumor bed thickness and varied from 80 to $120 \mathrm{KV}$. Lead corneal shielding was applied to protect the cornea if it wasn't involved with the tumor. Bolus was not required

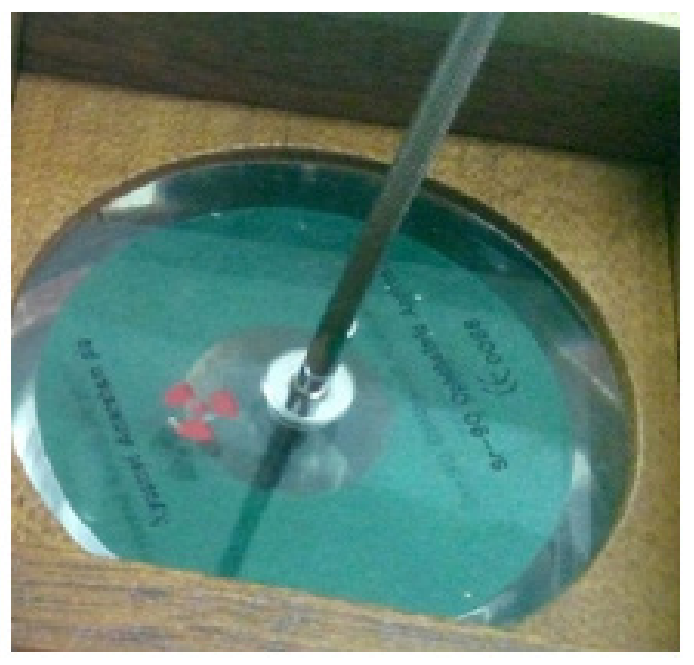

Figure 1. Strontium 90 Ophthalmic Applicator since the maximum delivered dose with KVRT is at the conjunctival surface. Every treatment plan was doublechecked by a second radiation oncologist in order to insure the accuracy of the radiotherapy treatment plan.

Post-operative ocular brachytherapy was either exclusive or used as a boost after external beam radiotherapy. The Strontium 90 ophthalmic applicator was applied to the exact location of the tumor bed with a minimal margin of $2 \mathrm{~mm}$ around the tumor bed borders. Dosimetric planification was made by a radiophysicist and a radiation oncologist. The prescribed dose to the tumor bed at $1 \mathrm{~mm}$ depth was 2 fractions of 17 Gy in case of exclusive post-operative brachytherapy and 1 fraction of 10 Gy when brachytherapy was applied as a boost after EBRT.

\section{Data collection}

Patient data were extracted from medical records and included patient age at diagnosis, sex, history of immunosuppression, presenting symptoms, tumor laterality, tumor basal diameter and thickness, histological type, treatment characteristics (type of surgery, surgical margins, radiation therapy technique, dose and fractionation) and patients' outcome (tumor control and treatment-related toxicities).

\section{Statistical analysis}

All statistical analyses were performed using the SPSS 22.0 statistical package.

Relapse-free survival and overall survival rates and curves were generated using the Kaplan-Meier method.

\section{Results}

Twenty four patients were included in our study: 19 men and 5 women. The mean age of our patients was 54 years (range: 20 to 84 years). Three patients had a history of immunosuppression for kidney transplantation in the first case, chronic lymphocytic leukemia in the second case and long-term corticosteroid therapy in the third case. One patient had a history of trachoma. The most common

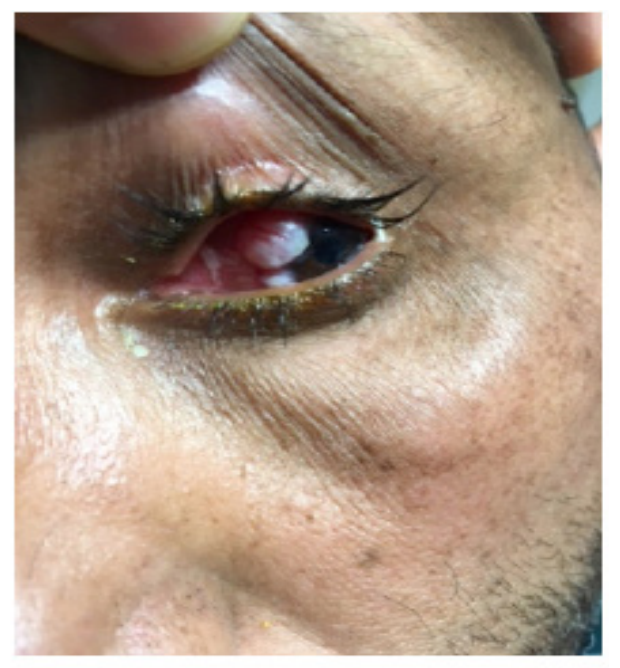

Figure 2. A Conjunctival Tumor Originating from the Limbus of the Left Eye 


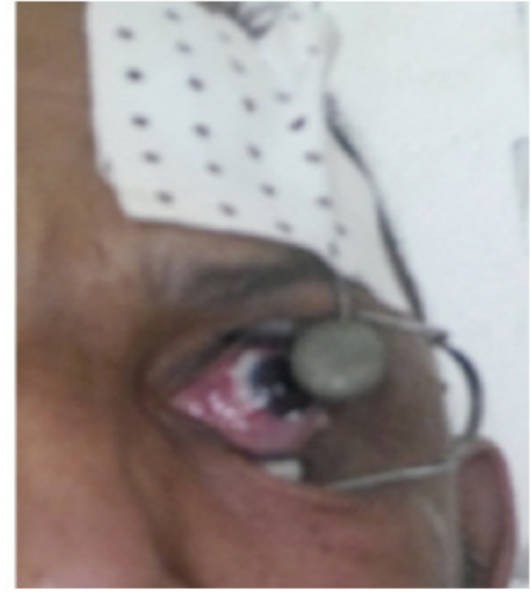

Figure 3. Eyelid Retractor and Corneal Lead Shielding for Conjunctival Kilovoltage Radiotherapy

presenting symptom was a painless ocular mass in 18 cases (Figure 2). Other presenting signs were the ocular pain in 3 cases, tearing in 2 cases and decreased vision in 2 cases.

The tumor was unilateral in all cases. It was located in the right eye in 11 cases and in the left eye in the remaining 13 cases. The tumor location within the conjunctiva was the limbus in 17 cases and the bulbar conjunctiva in 7 cases.

The mean basal diameter of the tumor was $11 \mathrm{~mm}$ (range 6 to $20 \mathrm{~mm}$ ). The mean tumor thickness was $4 \mathrm{~mm}$ (range 1 to $15 \mathrm{~mm}$ ).

The most frequent histological type was squamous cell carcinoma in 23 cases. One patient had a malignant conjunctival fibrohistiocytoma. Patients' characteristics and tumors' features are listed in Table 1.

Radiation therapy was post-operative for positive or narrow surgical margins all cases. Twenty two patients were treated with kilovoltage radiation therapy (KVRT). KVRT beams' energy depended on tumor bed thickness and was $80 \mathrm{KV}$ in 4 cases, $100 \mathrm{KV}$ in 7 cases and 120 $\mathrm{KV}$ in 11 cases. The mean delivered dose was $64 \mathrm{~Gy}$ (range: 60 to $70 \mathrm{~Gy}$ ) with 2 Gy per fraction and 5 fractions per week. An eyelid retractor was used to expose the tumor or the tumor bed, a corneal lead shielding was placed to protect the cornea (Figure 3) and patients were told to look at the fixed point during the radiotherapy session.

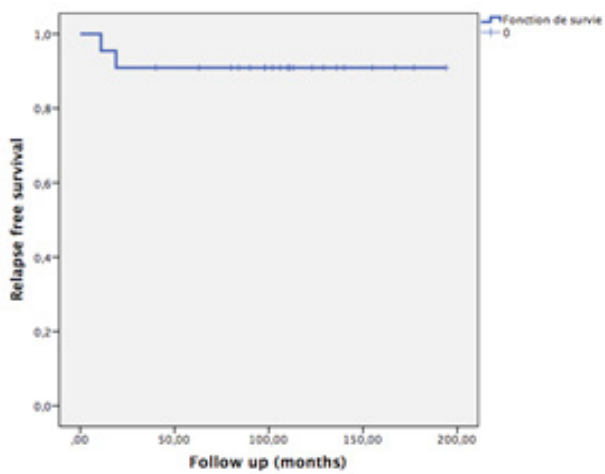

Figure 4. Kaplan Meier Relapse Free Survival Curve
Table 1. Patients' Characteristics and Tumors Features

\begin{tabular}{|c|c|}
\hline Feature & All patients $(n=24)$ \\
\hline Age (years) & $\begin{array}{c}\text { mean: } 54 \text {, range: } 20-84 \\
\text { years }\end{array}$ \\
\hline \multicolumn{2}{|l|}{$\operatorname{Sex}(n)$} \\
\hline male & 19 \\
\hline female & 5 \\
\hline \multicolumn{2}{|c|}{ History of immunosuppression (n) } \\
\hline yes & 3 \\
\hline no & 21 \\
\hline \multicolumn{2}{|l|}{ Presenting symptoms (n) } \\
\hline painless ocular mass & 18 \\
\hline ocular pain & 3 \\
\hline tearing & 2 \\
\hline decreased vision & 2 \\
\hline \multicolumn{2}{|l|}{ Tumor laterality (n) } \\
\hline right eye & 11 \\
\hline left eye & 13 \\
\hline Tumor basal diameter $(\mathrm{mm})$ & mean: 11 , range: $6-20$ \\
\hline Tumor thickness (mm) & mean: 4 , range: 1 - 15 \\
\hline \multicolumn{2}{|l|}{ Histological type (n) } \\
\hline squamous cell carcinoma & 23 \\
\hline fibrohistiocytoma & 1 \\
\hline \multicolumn{2}{|l|}{ TNM stage } \\
\hline T1N0M0 & 10 \\
\hline T2N0M0 & 14 \\
\hline
\end{tabular}

KVRT was associated with high-dose-rate Strontium 90 plaque brachytherapy in 4 cases. In these cases, the brachytherapy dose to the tumor bed at $1 \mathrm{~mm}$ depth was $10 \mathrm{~Gy}$ in one fraction, as a boost after a KVRT dose of 50-60 Gy. Two patients were treated with exclusive post-operative high-dose-rate Strontium 90 plaque brachytherapy ( 2 fractions of 17 Gy at $1 \mathrm{~mm}$ depth). Treatment characteristics are listed in Table 2.

After a median follow-up of 110 months, 19 patients were alive with no evidence of local recurrence in 17 patients. Two patients had a local recurrence and were referred to surgery. Three patients were dead without evidence of recurrence. Two patients were lost to follow

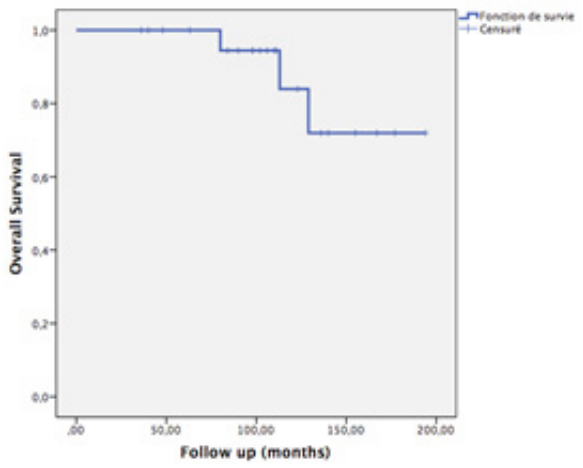

Figure 5. Kaplan Meier Overall Survival Curve 
Table 2. Treatment Characteristics

\begin{tabular}{lc}
\hline Treatment & $\begin{array}{c}\text { All patients } \\
(\mathrm{n}=25)\end{array}$ \\
\hline Kilovoltage radiotherapy $(80-120 \mathrm{KV})$ & 18 \\
$\begin{array}{l}\text { Kilovoltage radiotherapy + Strontium } 90 \\
\text { plaque brachytherapy (as a boost) }\end{array}$ & 4 \\
Strontium 90 plaque brachytherapy & 2 \\
\hline
\end{tabular}

up. Using Kaplan Meier survival analysis, the 5-year relapse-free survival rate was $90.9 \%$ (Figure 4 ). The 5-year overall survival rate was $86.4 \%$ (Figure 5 ).

Radiation-induced side effects were conjunctivitis in 17 patients, cataract in 15 patients, tearing in 13 patients and glaucoma in 2 patients.

\section{Discussion}

In this retrospective case series, radiation therapy was efficient to prevent post-operative recurrences in conjunctival malignancies with positive or close surgical margins.

Most conjunctival malignancies arise from or resemble a benign/premalignant counterpart. For example, conjunctival melanoma tends to arise from primary acquired melanosis, squamous cell carcinoma arises from conjunctival intraepithelial neoplasia, and lymphoma is presumed to arise from and can closely resemble benign reactive lymphoid hyperplasia [2].

Squamous cell intraepithelial neoplasia and carcinomatous disease can involve and primarily arise from the conjunctiva and cornea. This entity, referred to as ocular surface squamous neoplasia (OSSN), represents a spectrum of disease ranging from mild dysplasia to invasive squamous cell carcinoma [3]. OSSN most commonly occurs near the limbus, and like cutaneous squamous cell carcinoma, it more commonly occurs in older men with a history of risk factors, such as sun exposure, fair skin, immunosuppression, and smoking [3, 4]. Additionally, there may be a relationship between OSSN and concurrent infection with human papillomavirus type 16 , human immunodeficiency virus (HIV), or upregulation of matrix metalloproteinases [4-6].

These malignancies are more common in white patients and epithelial tumors are more frequently found in men [2]. Clinically, OSSN lesions typically present as fleshy conjunctival lesions with a gelatinous, leukoplakic, or papillary appearance. They are thought to arise from the limbal stem cells. OSSN lesions are most commonly found in the interpalpebral region involving the cornea and/or bulbar conjunctiva with the tarsal conjunctiva being less frequently involved [7].

OSSN has appearances ranging from flat or gelatinous areas of leukoplakia to nodular or papular lesions and may show significant vascularization and pigmentation [4]. The most common presenting complaints include eye irritation, foreign body sensation, pruritus, photophobia, decreased vision, and diplopia [4-8]. Local invasion of OSSN, most commonly to the cornea and sclera, occurs in about $40 \%$ of cases [4-8-9]. Deeper intraocular invasion is reported to occur in up to $13 \%$ of cases of conjunctival SCC [4-9]. Regional nodal metastasis to preauricular, submandibular, and cervical lymph nodes may occur but is relatively uncommon with a reported incidence of less than $1 \%[4-9]$.

Surgical excision with at least 3-4 mm tumor-free margins is the predominant treatment modality for operable OSSN [3]. Recurrence following surgical excision alone has been published to occur in approximately $30 \%$ of cases, and as high as $69 \%$ in those with documented positive surgical margins [10-11]. The importance of adequate surgical margins has been demonstrated in many studies with increased recurrence rates in those with incompletely excised tumors [3-12, 13]. Recurrence risk has been also reported to correlate with factors such as involvement of the tarsal surface, nasal location, higher AJCC stage and high-grade lesions [3-4, 14].

There is currently little evidence for the superiority of one adjuvant therapy over another $[15,16]$. Intraoperative adjuvant agents including cryotherapy [17], absolute alcohol [18], and mitomycin C [19] are now often used to reduce the risk of local recurrence.

Overall rates of recurrence following wide excisional biopsy combined with cryotherapy are at $8 \%$ to $21 \%$ $[3,11,17]$.

Topical chemotherapy has been used as both primary and adjuvant therapy for OSSN. Drugs used have included topical mitomycin C, 5-fluorouracil, and interferon alpha-2 b [20-22]. While both topical 5-fluorouracil and topical mitomycin $\mathrm{C}$ have been found to be very effective in preventing recurrence, these agents are associated with ocular surface and eyelid irritation and toxic effects [23]. Topical and subconjunctival administration of interferon alpha-2 b has shown excellent efficacy in preventing recurrence and has a much better side effect profile than mitomycin $\mathrm{C}$ but may require longer treatment than 5-fluorouracil or mitomycin C [24]. Perilesional subconjunctival injection of bevacizumab has recently been shown to be effective in the treatment of conjunctival lesions in a relatively small case series but the authors observed that this treatment had no significant effect on corneal lesions [25].

Radiation therapy has been also used as an adjuvant treatment in incompletely resected conjunctival malignancies to reduce the risk of post-operative recurrences. Deep tissues-sparing techniques such as kilovoltage radiotherapy, electron beams, brachytherapy or more recently proton beam therapy have been used to treat the conjunctival tumor bed. Kilovoltage radiotherapy was mainly used in skin cancers [26]. The ease of shielding and the ability to minimize field size allows the use of this technique in the radiotherapy of conjunctival malignancies. However, whilst dose from primary photons is easily attenuated to relatively insignificant levels by a few millimeters of lead or tungsten, scattered photons from outside the shielded area can provide over $25 \%$ of the prescribed dose [27].

Proton beam therapy has been used in a French ocular oncologic center about 15 patients either for recurrent or incompletely resected conjunctival squamous cell 
carcinoma [28]. Prescribed doses to the target volume varied from 40 Gy to $60 \mathrm{~Gy}$. After a median follow-up of 39.1 months, the tumor control rate was up to $86.8 \%$, with acceptable side effects.

Plaque brachytherapy has also been used to control residual microscopic tumor following surgical resection of conjunctival squamous cell carcinoma [29]. Beta radiation provides precise, low penetration radiotherapy with sharp margins [11]. In cases of superficial conjunctival squamous cell carcinoma, reports using strontium-90 or ruthenium-106 plaque brachytherapy revealed nearly $100 \%$ success rates [30-31]. Adjuvant ocular plaque brachytherapy has also been used in the management of conjunctival malignancies. In a previous study, about 123 patients with OSSN treated by excision followed by strontium 90 brachytherapy, Kearsley et al. [30] reported a recurrence rate of $2.4 \%$ with minimal complications. In a series of 69 patients with carcinoma in situ or squamous cell carcinoma of the conjunctiva, from a population with a high prevalence of HIV infection, treated with resection and adjuvant strontium 90 brachytherapy, the recurrence rate was $11.6 \%$ at a median of 5 months [16].

Gamma radiotherapy using iodine 125 has also been explored as an adjuvant treatment to excision for invasive conjunctival squamous cell carcinoma because it has a deeper penetrability compared with beta radiation. Iodine-125 plaque brachytherapy was evaluated in a retrospective interventional case series about 15 eyes with invasive conjunctival squamous cell carcinoma [11]. The ocular Iodine-125 plaque was applied in for a mean apex dose of 56 Gy. Over a mean follow-up of 41 months, local tumor control was achieved in all 15 cases $(100 \%)$. However, 4 cases showed further distant conjunctival tumor recurrence remote from the site of radiotherapy with positive orbital involvement at a mean of 5 months post-radiotherapy, necessitating enucleation or orbital exenteration. Radiation complications included cataract, iris telangiectasia, corneal epithelial defect, corneal edema, and glaucoma.

In Conclusion, post-operative radiation therapy using kilovoltage radiotherapy and/or strontium-90 plaque brachytherapy allows good local control with acceptable complications in incompletely resected conjunctival malignancies. Management of these tumors needs a broad collaboration between ophthalmologists and radiation oncologists, to allow a conservative treatment with the lowest rates of local recurrence.

\section{References}

1. Shields CL, Alset AE, Boal NS, et al. Conjunctival tumors in 5002 cases. Comparative analysis of benign versus malignant counterparts. The 2016 James D. Allen Lecture. Am J Ophthalmol, 2017;173, p.106-33.

2. Shields CL, Chien JL, Surakiatchanukul T, et al. Conjunctival Tumors: Review of clinical features, risks, biomarkers, and outcomes--The 2017 J. Donald M. Gass Lecture. Asia Pac J Ophthalmol (Phila), 2017 ;6, p.109-20.

3. Galor A, Karp CL, Oellers P, et al. Predictors of ocular surface squamous neoplasia recurrence after excisional surgery.
Ophthalmology, 2012;119, p.1974-81.

4. Yin VT, Merritt HA, Sniegowski M, Esmaeli B. Eyelid and ocular surface carcinoma: diagnosis and management. Clin Dermatol, 2015;33, p.159-69.

5. Di Girolamo N. Association of human papilloma virus with pterygia and ocular-surface squamous neoplasia. Eye (Lond), 2012;26, p.202-11.

6. Di Girolamo N, Atik A, McCluskey PJ, et al. Matrix metalloproteinases and their inhibitors in squamous cell carcinoma of the conjunctiva. Ocul Surf, 2013;11, p.193-205.

7. Sayed-Ahmed IO, Palioura S, Galor A, Karp CL. Diagnosis and Medical Management of Ocular Surface Squamous Neoplasia. Expert Rev Ophthalmol, 2017 ;12, p.11-9.

8. Cervantes G, Rodriguez Jr AA, Leal AG. Squamous cell carcinoma of the conjunctiva: Clinicopathological features in 287 cases. Can J Ophthalmol, 2002;37, p. 4-9.

9. Tunc M, Char DH, Crawford B, et al. Intraepithelial and invasive squamous cell carcinoma of the conjunctiva: Analysis of 60 cases. Br J Ophthalmol, 1999;83, p. 98-103.

10. Sudesh S, Rapuano CJ, Cohen EJ, Eagle RC Jr, Laibson PR. Surgical management of ocular surface squamous neoplasms. Cornea, 2000;19, p. 278-83.

11. Arepalli S, Kaliki S, Shields CL, Emrich J, Komarnicky L, et al. Plaque radiotherapy in the management of scleralinvasive conjunctival squamous cell carcinoma: an analysis of 15 eyes. JAMA Ophthalmol, 2014;132, p. 691-6.

12. Erie JC, Campbell RJ, Liesegang TJ. Conjunctival and corneal intraepithelial and invasive neoplasia. Ophthalmology, 1986;93, p. 176-83.

13. Tabin G, Levin S, Snibson G, et al. Late recurrences and the necessity for long-term follow-up in corneal and conjunctival intraepithelial neoplasia. Ophthalmology, 1997;104, p. 485-92.

14. Yousef YA, Finger PT. Squamous carcinoma and dysplasia of the conjunctiva and cornea an analysis of 101 cases. Ophthalmology, 2012;119, p. 233-40.

15. Gichuhi S, Irlam JH. Interventions for squamous cell carcinoma of the conjunctiva in HIV-infected individuals. Cochrane Database Syst Rev, 2013;2, CD005643.

16. Lecuona K, Stannard C, Hart G, et al. The treatment of carcinoma in situ and squamous cell carcinoma of the conjunctiva with fractionated strontium- 90 radiation in a population with a high prevalence of HIV. Br J Ophthalmol, 2015;99, p. 1158-61.

17. Peksayar G, Altan-Yaycioglu R, Onal S. Excision and cryosurgery in the treatment of conjunctival malignant epithelial tumours. Eye (Lond), 2003;17, p. 228-32.

18. Shields JA, Shields CL, De Potter P. Surgical management of conjunctival tumors: the 1994 Lynn B. McMahan Lecture. Arch Ophthalmol, 1997;115, p. 808-15.

19. Siganos CS, Kozobolis VP, Christodoulakis EV. The intraoperative use of mitomycin-C in excision of ocular surface neoplasia with or without limbal autograft transplantation. Cornea, 2002;21, p. 12-6.

20. Midena E, Angeli CD, Valenti M, et al. Treatment of conjunctival squamous cell carcinoma with topical 5-fluorouracil. Br J Ophthalmol, 2000;84, p. 268-72.

21. Karp CL, Moore JK, Rosa Jr RH. Treatment of conjunctival and corneal intraepithelial neoplasia with topical interferon alpha-2 b. Ophthalmology, 2001;108, p. 1093-8.

22. Gupta A, Muecke J. Treatment of ocular surface squamous neoplasia with mitomycin C. Br J Ophthalmol, 2010;94, p. $555-8$.

23. Bahrami B, Greenwell T, Muecke JS. Long-term outcomes after adjunctive topical 5-flurouracil or mitomycin $\mathrm{C}$ for the treatment of surgically excised, localized ocular surface 
squamous neoplasia. Clin Exp Ophthalmol, 2014;42, p. 317-22.

24. Karp CL, Galor A, Chhabra S, et al. Subconjunctival/ perilesional recombinant interferon alpha $2 \mathrm{~b}$ for ocular surface squamous neoplasia: A 10-year review. Ophthalmology, 2010;117, p. 2241-6.

25. Faramarzi A, Feizi S. Subconjunctival bevacizumab injection for ocular surface squamous neoplasia. Cornea, 2013;32, p. 998-1001.

26. Amdur RJ, Kalbaugh KJ, Ewald LM, et al. Radiation therapy for skin cancer near the eye: kilovoltage $x$-rays versus electrons. Int J Radiat Oncol Biol Phys, 1992;23, p. 769-79.

27. Baker CR, Luhana F, Thomas SJ. Absorbed dose behind eye shields during kilovoltage photon radiotherapy. Br J Radiol, 2002;75, p. 685-8.

28. Caujolle JP, Maschi C, Chauvel P, Herault J, Gastaud P. Surgery and additional protontherapy for treatment of invasive and recurrent squamous cell carcinomas: technique and preliminary results. J Fr Ophtalmol, 2009;32, p. 707-14.

29.) Shields JA, Shields CL, Freire JE, Brady LW, Komarnicky L. Plaque radiotherapy for selected orbital malignancies. Ophthal Plast Reconstr Surg, 2003;19, p. 91-5.

30. Kearsley JH, Fitchew RS, Taylor RG. Adjunctive radiotherapy with strontium-90 in the treatment of conjunctival squamous cell carcinoma. Int J Radiat Oncol Biol Phys, 1988;14, p. 435-43.

31. Zehetmayer M, Menapace R, KulnigW. Combined local excision and brachytherapy with ruthenium-106 in the treatment of epibulbar malignancies. Ophthalmologica, 1993;207, p. 133-9.

\section{(c) (1) (2)}

This work is licensed under a Creative Commons AttributionNonCommercial 4.0 International License. 